\title{
QT corrected and QTc dispersion across different phases of menstrual cycle- A cross-sectional study
}

\author{
Nirmala S. Anand ${ }^{1, *}$, Shivaprasad S. Goudar ${ }^{2}$ \\ ${ }^{\mathbf{1}}$ Assistant Professor, ${ }^{2}$ Professor, Dept. of Physiology, Jawaharlal Nehru Medical College, Belgaum, Karnataka, India
}

*Corresponding Author: Nirmala S. Anand

Email: drnirm79@gmail.com

Received: $17^{\text {th }}$ November, 2017

Accepted: $24^{\text {th }}$ May, 2018

\begin{abstract}
Introduction: The gonadal hormones accompanying the menstrual cycle in a female affect the ventricular repolarization regionally in the cardiac muscle as well as affects its recovery time both of which are $\mathrm{QT}_{\mathrm{c}} \mathrm{AND}_{\mathrm{QT}} \mathrm{m}_{\mathrm{d}}$ measured conventionally using a non-invasive ECG. A prolonged $\mathrm{QT}_{\mathrm{c}}$ and $\mathrm{QT}_{\mathrm{d}}$ are predictors of cardiac morbidity and mortality.

Aim: The aim of the present study was to examine whether the cardiac ventricular repolarization is altered during different phases of menstrual cycle by the endogenous gonadal hormones.

Materials and Methods: Thirty eumenorrhic females were examined using 12 lead ECG during the follicular and luteal phases of menstrual cycle.

Statistical Analysis: Data was analysed statistically using student's paired t-test.

Results: It was observed that the heart rate in follicular phase was $(78.8 \pm 7.48)$ while in luteal $(84 \pm 8.17)$, R-R interval in follicular was $(82 \pm 5.89)$ while in luteal phase was $(77 \pm 3.69)$ QT interval in follicular was $(0.39 \pm 0.09)$ while in luteal phase was $(0.33 \pm 0.08), \mathrm{QT}_{\mathrm{c}}$ in follicular was $(0.43 \pm 0.03)$ while in luteal phase was $(0.39 \pm 0.03), \mathrm{QT}_{\mathrm{d}}$ in follicular was $(67 \pm 2.30)$ while in luteal phase was $(58 \pm 4.08)$.

Conclusion: We hence elucidate interactions between the sex steroids and cardiac conduction dynamics which is characterized by a prolonged $\mathrm{QT}_{\mathrm{c}}$ and $\mathrm{QT}_{\mathrm{d}}$ during the follicular phase.
\end{abstract}

Keywords: Endogenous, Gonadal, Menstrual cycle, Repolarization.

\section{Introduction}

Menstruation involves rhythmic cyclical changes in all the reproductive organs of a female which in turn is due to the interplay of endogenous hormones i.e.oestrogen and progesterone. These gonadal hormones are associated with various homeostatic changes in various organ systems in anticipation to fertilization if at all. Apart from its traditional role in affecting the reproductive organs the presence of receptors for the sex steroids on the cardiovascular as well as the level of medulla is well established hence it is subjudiced that the changes in the functioning of these systems cyclically are inherent to the biological rhythm. Multiple studies conducted on males and females have studied the propensity to develop cardiac rhythm abnormalities and the most feared torsa des pointes which occurs in the absence of structural deformities and can lead to ventricular fibrillation and tendency to develop MI, it was observed that females have a distinct advantage over the age matched male counterparts showing a delay in the onset of cardiac abnormalities. The data tends to skew as a female turns postmenopausal with no difference in the morbidity or mortality rates thereafter. ${ }^{1,2}$

The ECG is a simple non-invasive diagnostic tool used to diagnose cardiac abnormalities. The QT interval (measured from the initial Q-wave deflection to the end of the $\mathrm{T}$ wave) records the ventricular depolarization and repolarization of both the ventricles but is variable as it is dependent on the RR interval, so several formulae have been devised to calculate a corrected QT. The QT interval, QT interval corrected (QTc) using Bazett and Fredricia formula and its dispersion $\left(\mathrm{QT}_{\mathrm{d}}\right)$ is a measure of ventricular repolarization and ventricular recovery time and differences in the repolarization times across the entire ventricular musculature, and its prolongation has been linked to the occurrence of cardiac arrhythmias. ${ }^{3,4}$ An abnormal $\mathrm{QT}_{\mathrm{c}}$ is one which is longer than $0.44 \mathrm{~s}$ even though physiologically, some females may have $\mathrm{QT}_{\mathrm{c}}$ up to $0.46 \mathrm{~s}$. The treating physician should be vigilant as female gender and the prolongation of QT is a cumulative risk factor for development of torrential arrhythmias which should be borne in mind prior to instituting a drug regime which has effects in the cardiac conduction system since certain drugs are known to cause fatal drug induced arrhythmias. There are numerous studies in literature which have correlated HRV changes to the phases of menstrual cycle but sex differences in ECG findings is a matter of debate. The QTc interval which is notably increased in females compared to males owing to their slower resting heart rates and R-R intervals and an associated steep QT-to-RR ratio which increases the likelihood to rhythm abnormalities. ${ }^{5-8}$ There is solicited proof that these QTc changes are not present since birth $^{9}$ and the change in the QTc characteristics occur post-pubertal associated with a surge in the levels of endogenous gonadal hormones. ${ }^{10}$ The prolongation of QTc during pregnancy ${ }^{11}$ and longer baseline QTc in post pubertal women ${ }^{5,12}$ reinstates the role of sex 
hormones in altering the cardiac electrogenic properties. Numerous animal studies have demonstrated the effect of gonadal hormones on cardiac myocyte as well as the conduction system but the results remain inapplicable to humans due to paucity of studies conducted on recording the electrical phenomenon. Converging line of data on inability to reach a consensus and conflicting reports on the effects of sex steroids on ECG recordings especially repolarization with the menstrual cycle ${ }^{13-16}$ has hampered the assessment of female gender as to being a risk factor for arrhythmogenesis. The results may aide the physicians in treatment modalities which can be made more cycle specific as well as hormone replacement therapy instituted if at all be in sync with the biological rhythm and at the same time the physiologist may solve the nexus around the influence of sex hormones and cardiac repolarization properties.

\section{Materials and Methods}

Study Design: Cross-sectional

Duration: December 2011 till February 2012

Source of Data: In the present study the data was collected from the students of first year M.B.B.S for the academic year 2011.

Sample Size: Thirty eumenorrhic girls aged 17 -20 years of age studying their first year MBBS course were selected

Sample Size Estimation- ${ }^{17}$

Expected Reduction $-($ Mean $)=\mathrm{d}=20$

$\mathrm{SD}=40=\sigma$

$\dot{\alpha}=0.05$ One sided $\quad Z \dot{\alpha}=1.65$

$\beta=0.2$ Power $80 \% \quad Z \beta=0.84$

$\mathrm{n}=[(\mathrm{Z} \alpha \dot{\alpha}+\mathrm{Z} \beta) \sigma / \mathrm{d}]^{2}=24.8=25=30$

Based on sample size calculation 30 MBBS phase 1 females aged 17-20 years who are eligible were enrolled at the time of data collection.

Inclusion Criteria: Thirty eumenorrhic girls aged 17 20 years of age studying their MBBS course with regular cycle duration of 28 days at least prior to 2 months of the study, having no well-defined premenstrual tension or no medical, endocrinological, psychiatric or gynaecological problems were enrolled.

Exclusion Criteria: Subjects who had any menstrual cycle irregularities, dysmenorrhea, menorrhagia, or consuming drugs like cough suppressants, history of smoking or drug abuse antidepressant, oral contraceptive pill, drugs that alter the cardiovascular functions, history or clinical suspicion of ischemic or structural heart disease, any kind of conduction defect or antiarrhythmic drug use or history of hypertension, diabetes mellitus were excluded from the study. Females engaging in active exercise i.e.- 3 times/week are excluded from the study since the work extends to sedentary females.

Voluntary informed written consent was obtained from all participants, and the experiment protocol was approved by Institutional Ethics committee on human research of the college. A detailed menstrual history regarding the total duration, regularity, flow was collected from every participant prior to enrollment. ${ }^{17}$

The entire purpose along with a detailed description of the study protocol was given to all the subjects prior to beginning of the test\& examination carried out at same time of the day. ${ }^{17}$

Considering the first day of bleeding as Day 1, the phases marked out were and confirmed by basal body temperature monitoring:

1. Follicular $\left(10^{\text {th }}\right.$ day $)$

2. Luteal $\left(20^{\text {th }}\right.$ day $)$.

\section{Recording}

The subject was given a rest in supine position for a period of 20 mins following which ECG was recorded at a paper speed of $25 \mathrm{~mm} / \mathrm{s}$ and a calibration of 1 $\mathrm{mv}=10 \mathrm{~mm}$ and the QT recorded in all possible leads with the interval considered from the onset of the QRS complex to the end of the $T$ wave The end of the $T$ wave was defined as intersection of the terminal limb of the $\mathrm{T}$ wave with the isoelectric baseline. ${ }^{18}$ The longest and the shortest QT intervals across 12 leads were defined as the maximum $\mathrm{QT}\left(\mathrm{QT}_{\max }\right)$ and the minimum QT $\left(\mathrm{QT}_{\min }\right)$ intervals, respectively. QTC was corrected for heart rate by using the Bazett formula and defined as corrected $\mathrm{QT}_{\max }\left(\mathrm{QT}_{\operatorname{maxc}}\right)$ and corrected $\mathrm{QT}_{\text {min }}\left(\mathrm{QT}_{\text {minc }}\right)$, respectively. ${ }^{19,20} \mathrm{QT}_{\mathrm{c}}$ dispersion $\left(\mathrm{QT}_{\mathrm{cd}}\right)$ was defined as the difference between $\mathrm{QT}_{\operatorname{maxc}}$ and $\mathrm{QT}_{\text {minc. Fridericia formula was also used since it }}$ provided for rate-adjustment and is devoid of many errors. ${ }^{21-23}$ Intervals between two consecutive R-waves were defined as RR interval.

1. Bazett: $\mathrm{QTc}=\mathrm{QT}(\mathrm{RR}) 1 / 2$

2. Fridericia: $\mathrm{QTc}=\mathrm{QT}(\mathrm{RR}) 1 / 3$

\section{Results}

The results from the study show that the indices which represent ventricular repolarization are all prolonged during the follicular phase of menstrual cycle. This suggests that females are potentially at high risk of developing ventricular arrhythmias during the follicular phase.

Table 1: Shows the baseline demographic characteristics of the population. ${ }^{17}$

\begin{tabular}{|l|c|}
\hline Age(yrs.) & $18.3 \pm 0.66(17-20)$ \\
\hline Weight $(\mathrm{kg})$ & $56.7 \pm 7.55(47-65)$ \\
\hline Height $\left(\mathrm{m}^{2}\right)$ & $1.56 \pm 0.04(1.51-1.68)$ \\
\hline
\end{tabular}

NS-not significant, ${ }^{*}$-statistically significant at $\mathrm{p}<0.05$

Table 1 shows the demographic profile of the participants. It is evident that most of the participants are of the mean age group of 18 years and average weight of $56 \mathrm{kgs}$. 
Table 2: Heart rate \& repolarization indices across different phases of menstrual cycle

\begin{tabular}{|l|c|c|c|}
\hline & Follicular & Luteal & P value \\
\hline Heart rate(b/min) & $78.8 \pm 7.48$ & $84 \pm 8.17$ & $0.003^{*}$ \\
\hline QT $(\mathrm{msec})$ & $0.39 \pm 0.09$ & $0.33 \pm 0.08$ & $\leq 0.001^{*}$ \\
\hline QTc $(\mathrm{msec})$ & $0.43 \pm 0.03$ & $0.39 \pm 0.03$ & $\leq 0.001^{*}$ \\
\hline
\end{tabular}

NS-not significant, ${ }^{*}$-statistically significant at $\mathrm{p}<0.05$.

Table 2 shows the mean Heart rates and ventricular repolarization indices of the participants. The results of the table suggest a higher heart rate during the luteal phase while the ventricular repolarization indices like QT and QTc were prolonged in the follicular phase as compared to the luteal phase which was statistically significant.

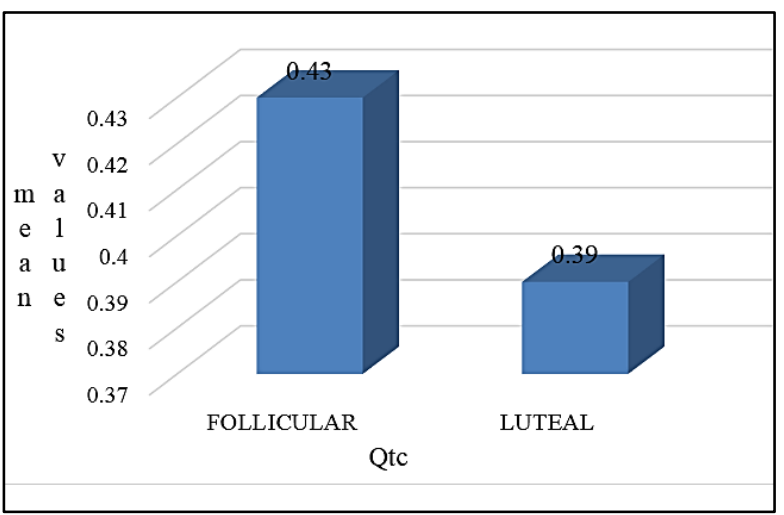

Fig. 1: Qtc during different phases of menstrual cycle

Table 3: QT dispersion \& RR intervals across different phases of menstrual cycle

\begin{tabular}{|l|c|c|c|}
\hline & Follicular & Luteal & P value \\
\hline $\begin{array}{l}\text { R-R interval } \\
\text { (msec) }\end{array}$ & $82 \pm 5.89$ & $77 \pm 3.69$ & $0.30^{\mathrm{NS}}$ \\
\hline $\mathbf{Q T}_{\mathbf{d}}(\mathbf{m s e c})$ & $67 \pm 2.30$ & $58 \pm 4.08$ & $0.001^{*}$ \\
\hline
\end{tabular}

NS-not significant, ${ }^{*}$-statistically significant at $\mathrm{p}<0.05$.

Table 3 shows the mean RR intervals and $\mathrm{QT}_{\mathrm{d}}$ which measures the heterogeneity of regional ventricular repolarization of the participants is statistically prolonged in the follicular phase as compared to the luteal phase.

\section{Discussion}

The results derived from our study suggest a prolonged QT interval, $\mathrm{QT}_{\mathrm{C}}$ and $\mathrm{QT}_{\mathrm{d}}$ during the follicular phase as compared to the luteal phase, thus confirming that endogenous gonadal hormones i.e. oestrogen and progesterone affect cardiac ventricular repolarization as well as exhibit a regional heterogeneticity in its actions on the cardiac musculature, with oestrogen prolonging the repolarization indices and the progesterone exerting an anti-oestrogenic and androgenic property and antagonizing the actions of oestrogen and shortening the duration of cardiac action potential. The fluctuating levels of oestrogen and progesterone exert a genomic and non- genomic hormone induced changes at the level of cardiac musculature.

The results derived from our study are in similar lines with a study which signifies that the QT interval values fluctuate parallel to the surges in gonadal hormones associated with the menstrual cycle. ${ }^{13}$ On the other hand there are contradictory reports from certain studies where no association was found between oestrogen and its cardio-protective role on the cardiovascular system..$^{24,25}$ Our results are in sync with the results of a study wherein they observed that during a single cycle it was progesterone and oestrogen which affected the ventricular repolarization in women, with the endogenous progesterone shortening the action potential while oestrogen counterbalances it by prolonging it. ${ }^{26}$ The possible molecular mechanism how oestrogen prolongs the action potential is by inhibiting the potassium channels which are responsible for ventricular repolarization and also hormone induced depletion in the mRNA levels coding for the potassium rectifier channels, while in the animal models it was known to decrease the $\mathrm{Ic}_{\mathrm{Al}}$ as well as inward rectifying potassium channels at physiological doses..$^{27-29}$ The shorter QT interval observed during the luteal phase may be attributed to the high levels of progesterone which is known to decrease calcium channel current and increases potassium channel currents. The effects of progesterone have been studied in a guinea pig model, where it shortened the AP duration through up regulation of $\mathrm{I}_{\mathrm{Ks}}$ currents and down regulation of $\mathrm{I}_{\mathrm{Ca}}$, L currents. ${ }^{30}$ The risk of sudden cardiac death in patients with myocardial infarction, heart failure, and hypertrophic cardiomyopathy has been attributed to prolonged Qt interval. ${ }^{31-33}$ and is a risk factor for sudden cardiac death in hypertensive patients with left ventricular hypertrophy $(\mathrm{LVH}){ }^{31,32}$ The endogenous gonadal hormones of menstrual cycle alter the cardiac action potential kinetics with oestrogen in the follicular phase prolonging it and a progesterone surge during the luteal phase reversing it by antagonizing the actions of oestrogen.

Implications: There is sufficient line of data to prove that the post-menopausal state is an independent risk factor along with female gender for the development and progression of cardiovascular diseases which corroborates the modulatory role of endogenous hormones in cardiac conduction. The issue which remains to be resolved is of oestrogen conferring cardio protective role on the cardiovascular system with multiple studies suggesting the same,,$^{31,34,35}$ the delay in onset of cardiac adversities towards menopause 
compared to age matched males imbibes the role of hypo oestrogenic state facilitating $i^{1,2}$ while certain studies have reported negative outcomes with hormone replacement therapy in post-menopausal women contradicts the traditional cardio-protective role. ${ }^{36,37} \mathrm{~A}$ review of the food and drug administration database revealed a prediclition of females to develop torrential arrhythmias after consuming variety of drugs, such as antihistamines, antimalarials, certain antibiotics etc which have the potential to block potassium channels, thereby prolonging the QT interval on the ECG. ${ }^{28}$ The probable implication from such type of studies would be the potential use of progesterone containing analogues in treatment of conditions having long QT syndromes as well as caution be exercised when certain drugs known to affect the refractory periods are to be prescribed in females.

Limitations and Future Scope: Actual hormone estimation was not conducted due to paucity of funds and technical problems. Such studies should be conducted in larger population to get to the results. Future studies must be conducted to elucidate an association between the levels of sex steroids and their prognostic cardiovascular implications. Studies should include $\mathrm{QT}_{\mathrm{d}}$ on population suffering from cardiovascular conditions like hypertension, arrhythmias, MI and the female gender to strike an association between the two since $\mathrm{Qt}_{\mathrm{d}}$ and $\mathrm{QT}_{\mathrm{c}}$ have evolved as the biomarkers of predicting cardiac adversities and the risk of sudden death. ${ }^{38}$

\section{References}

1. T. Gordon, W.B. Kannel, M.C. Hjortland, P.M. Mc Namara. Menopause and coronary heart disease. The Framingham Study, Ann Intern Med. 1978;89:157-161.

2. V. Bittner. Menopause, age, and cardiovascular risk: a complex relationship. J Am Coll Cardiol. 54;2009:23742375.

3. Malik M, Batchvarov VN. Measurement, interpretation and clinical potential of QT dispersion. J Am Coll Cardiol. 2000;36:1749-66.

4. Malik M, Batchvarov VN. Measurement, interpretation and clinical potential of QT dispersion. J Am Coll Cardiol. 2000;36:1749-66.

5. Bazett HC. An analysis of the time-relations of electrocardiograms. Heart. 1920;7:353-370.

6. Goldberg RJ, Bengtson J, Chen ZY, Anderson KM, Locati E, Levy D. Duration of the QT interval and total and cardiovascular mortality in healthy persons (The Framingham Heart Study experience). Am J Cardiol. 1991;67:55-58.

7. Gonzalez R, Gomis-Tena J, Corrias A, Ferrero JM, Rodriguez B, Saiz J. Sex and age related differences in drug induced QT prolongation by dofetilide under reduced repolarization reserve in simulated ventricular cells. Conference proceedings: Annual International Conference of the IEEE Engineering in Medicine and Biology Society IEEE Engineering in Medicine and Biology Society Conference. 2010:3245-3248.

8. Dart AM, Du XJ, Kingwell BA. Gender, sex hormones and autonomic nervous control of the cardiovascular system. Cardiovasc Res. 2002;53:678-687.
9. Kligfield P, Lax KG, Okin PM. QT interval-heart rate relation during exercise in normal men and women: definition by linear regression analysis. J Am Coll Cardiol. 1996;28:1547-1555.

10. Stramba-Badiale M, Spagnolo D, Bosi G, Schwartz PJ. Are gender differences in QTc present at birth? MISNES Investigators Multicenter Italian Study on Neonatal Electrocardiography and Sudden Infant Death Syndrome. Am J Cardiol. 1995;75:1277-1278.

11. Guy Salama and Glenna C. L. Bett. Sex differences in the mechanisms underlying long QT syndrome. Am J Physiol Heart Circ Physiol. 2014;307:H640-H648.

12. Lechmanova M, Kittnar O, Mlcek M, Slavicek J, Dohnalova A, Havranek S, Kolarik J, Parizek A. QT dispersion and T-loop morphology in late pregnancy and after delivery. Physiol Res. 2002;51:121-129.

13. Merri M, Benhorin J, Alberti M, Locati E, Moss AJ. Electrocardiographic quantitation of ventricular repolarization. Circulation. 1989;80:1301-1308.

14. Nakagawa M, Ooie T, Takahashi N, Taniguchi Y, Anan F, Yonemochi H, Saikawa T. Influence of menstrual cycle on QT interval dynamics. Pacing Clin Electrophysiol. 2006;29:607-613.

15. Endres S, Mayuga KA, Cristofaro A, Taneja T, Goldberger JJ, Kadish AH. Menstrual cycle and ST height. Ann Noninvasive Electrocardiol. 2004;9:121-126.

16. Hulot JS, Demolis JL, Riviere R, Strabach S, ChristinMaitre S, Funck-Brentano C. Influence of endogenous oestrogens on QT interval duration. Eur Heart J. 2003;24:1663-1667.

17. Burke JH, Goldberger JJ, Ehlert FA, Kruse JT, Parker MA, Kadish AH. Gender differences in heart rate before and after autonomic blockade: evidence against an intrinsic gender effect. Am J Med. 1996;100:537-543.

18. Anand NS, Goudar SS. Cardiovascular reactivity and pain perception to thermal noxious stimuli across different phases of menstrual Cycle. IJCAP. 2017;4(4):498-503.

19. J. Couderc, W. Zareba. Assessment of ventricular repolarization from body-surface ECGs in humans J. Morganroth, I. Gussak (Eds.), Cardiac safety of noncardiac drugs: practical guidelines for clinical research and drug development, Humana Press, Totowa, NJ (2005).

20. H.C. Bazett. The time relations of the blood-pressure changes after excision of the adrenal glands, with some observations on blood volume changes. $J$ Physiol, 1920;53:320-339.

21. C. Pater. Methodological considerations in the design of trials for safety assessment of new drugs and chemical entities. Curr Control Trials Cardiovasc Med. 2005;6:1.

22. J.H. Indik, E.C. Pearson, K. Fried, R.L. Woosley. Heart Rhythm. 2006;3:1003-1007.

23. S. Luo, K. Michler, P. Johnston, P.W. Macfarlane. A comparison of commonly used QT correction formulae: the effect of heart rate on the QTc of normal ECGs. $J$ Electrocardiol, 2004;37(Suppl.):81-90.

24. B. Strohmer, C. Schernthanere, B. Paulweber, M. Pichler. Gender-specific comparison of five QT correction formulae in middle-aged participants in an atherosclerosis prevention program. Med Sci Monit. 2007;13:CR165CR171.

25. K.M. Rexrode, J.E. Manson, I.M. Lee, P.M. Ridker, P.M. Sluss, N.R. Cook, J.E. Buring Sex hormone levels and risk of cardiovascular events in postmenopausal women. Circulation. 2003;108:1688-1693. 
26. Y. Chen, A. ZeleniuchJacquotte, A.A. Arslan, O. Wojcik, P. Toniolo, R.E. Shor e, et al. Endogenous hormones and coronary heart disease in postmenopausal. Atherosclerosis. 2011;216(2):414419.

27. Tara Sedlak, Chrisandra Shufelt, Carlos Iribarren, and C. Noel Bairey Merz. Sex Hormones and the QT Interval: A Review. Journal of Women's Health. 2012;21(9):933941.

28. Ebert SN, Liu XK, Woosley RL. Female gender as a risk factor for drug-induced cardiac arrhythmias: evaluation of clinical and experimental evidence. $J$ Womens Health. 1998;7(5):547-57.

29. Drici MD, Burklow TR, Haridasse V, Glazer RI, Woosley RL. Sex hormones prolong the QT interval and down regulate potassium channel expression in the rabbit heart. Circulation. 1996;94(6):1471-4.

30. Berger F, Borchard U, Hafner D, Pütz I, Weis TM. Effects of 17beta-estradiolon action potentials and ionic currents in male rat ventricular myocytes. Naunyn Schmiedebergs Arch Pharmacol. 1997;356(6):788-96.

31. Nakamura H. Kurokawa J. Bai CX, et al. Progesterone regulates cardiac repolarization through a nongenomic pathway: An in vitro patch-clamp and computational modeling study. Circulation. 2007;116:2913-2922.

32. Buja G, Miorelli M, Turrini P. Comparison of QT dispersion in hypertrophic cardiomyopathy between patients with and without ventricular arrhythmias and sudden death. Am J Cardiol. 1993;72.97-976.

33. Perkiomaki J, Koistinen MJ, Yli-Mayry S. Dispersion of the QT interval in patients with and without susceptibility to ventricular tachyarrhythmias after previous myocardial infarction. J Am Coll Cardiol. 1995;26:174-179.

34. Mayet J, Shahi M, McGrath K. Left ventricular hypertension and QT dispersion in hypertension. Hypertension. 1996;28:791-796.
35. G.A. Colditz, W.C. Willett, M.J. Stampfer, B. Rosner, F. E. Speizer, C.H. Hennekens.Menopause and the risk of coronary heart disease in women. $N$ Engl J Med. 1987;316:1105-1110.

36. F. Atsma, Y.T. van der Schouw, D.E. Grobbee, J.A. Kors, M.L. Bartelink. Lifetime endogenous estrogen exposure and electrocardiographic frontal $\mathrm{T}$ axis changes in postmenopausal women Maturitas. 2009;63;347-351.

37. R.L. Prentice, J.E. Manson, R.D. Langer, G.L. Anderson, M. Pettinger, R.D. Jackson et al. Benefits and risks of postmenopausal hormone therapy when it is initiated soon after menopause. Am J Epidemiol. 2009;170(1):1223.

38. J.E. Rossouw, G.L. Anderson, R.L. Prentice, A.Z. LaCroi x, C. Kooperberg, M.L. Stefanick, R.D.Jackson, S.A. Ber esford, B.V. Howard, K.C. Johnson, J.M. Kotchen, J. Ock ene. Risks and benefits of estrogen plus progestin in healthy postmenopausal women: principal results From the Women's Health Initiative randomized controlled trial. JAMA. 2002;288:321-333.

39. Higham PD, Campbell RWF. QT dispersion. Br Heart J. 1994;71:508-510.

How to cite this article: Anand N.S, Goudar S.S. QT corrected and QTc dispersion across different phases of menstrual cycle- A cross-sectional study. Indian J Clin Anat Physiol. 2018;5(4):478482. 